\title{
A CRIANÇA E O SEU DESENVOLVIMENTO EM DISCURSOS MÉDICOS E PEDAGÓGICOS QUE CIRCULARAM NO CONTEXTO PORTUGUÊS (SÉCULOS XVIII A XX)
}

\begin{abstract}
António Gomes Ferreira*
RESUMO: A partir do advento da modernidade, dinâmicas tecnológicas, científicas, econômicas, sociais e culturais propiciaram crescente interesse pela quantidade e pela qualidade das pessoas e, consequentemente, por uma maior atenção ao crescimento e ao desenvolvimento da criança. A confluência dessas condições levaram a que se elaborasse uma racionalidade que, partindo do ancestral saber sobre o crescimento das pessoas, concedesse maior atenção às condições que o condicionavam, bem como às características que o podiam explicitar. O objetivo deste trabalho é apresentar dados provenientes da literatura médica e da literatura pedagógica impressa em Portugal, com vista a possibilitar uma compreensão sobre como foi perspectivado o desenvolvimento da criança entre os finais do século XVIII e o primeiro terço de Novecentos. É nosso propósito incidir tanto sobre dados de natureza somática como psicológica apresentados nas referidas literaturas, bem como sobre as concepções de desenvolvimento aí expressas.

Palavras-chave: Infância; Desenvolvimento; Pedologia.
\end{abstract}

CHILD AND THEIR DEVELOPMENT THROUGH MEDICAL AND PEDAGOGICAL LITERATURE CURRENTLY AVAILABLE IN THE PORTUGUESE LANGUAGE (18TH TO 20TH CENTURIES)

ABSTRACT: Since the advent of modernity, technological, scientific, economic, social and cultural dynamics have fostered a growing interest in the quantity and quality of people, and consequently in child's growth and development. The confluence of these conditions gave rise to a kind of rationality that, starting from the ancestral knowledge of people's growth, focused on the issues that influenced growth, as well as on the characteristics that could explain it. The aim of this work is to present data from medical and pedagogical literature printed in Portugal, with a view to promote an understanding of how child's development was perceived since the end of the 18th century up to the first third of the 20th century. It is our goal to focus on somatic and psychological data available on the aforementioned literature, as well as on the perceptions of development.

Keywords: Childhood; Development; Pedology.

\footnotetext{
* Doutor em Ciências da Educação; Professor e Subdiretor da Faculdade de Psicologia e de Ciências da Educação da Universidade de Coimbra, Portugal. E-mail: antonio@fpce.uc.pt
} 
Sem querermos entrar na discussão sobre o tão polêmico sentimento de infância, admitimos que as crianças de tempos diferentes da história estiveram sujeitas a compreensões diferentes sobre o que representavam e sobre como encarar o seu desenvolvimento. Se ao longo dos séculos que antecederam a afirmação da ciência moderna, o pensamento sobre a criança foi, sobretudo, condicionado pela interpretação da Igreja e pela gestão do conhecimento legado pela Antiguidade, não há dúvida de que a partir do advento da modernidade se geraram dinâmicas tecnológicas, científicas, econômicas, sociais e culturais que propiciaram crescente interesse pela quantidade e pela qualidade das pessoas e, consequentemente, por uma maior atenção ao crescimento e ao desenvolvimento da criança. A confluência dessas condições levou a que se elaborasse uma racionalidade que, partindo do ancestral saber sobre o crescimento das pessoas, concedesse maior atenção às condições que o condicionavam, bem como às características que o podiam explicitar. $\mathrm{O}$ objetivo deste nosso trabalho é apresentar dados provenientes da literatura médica e da literatura pedagógica impressa em Portugal, tendo em vista possibilitar uma compreensão sobre como foi perspectivado o desenvolvimento da criança entre os finais do século XVIII e o primeiro terço de Novecentos.

Ao pretendermos abordar historicamente a compreensão do desenvolvimento da criança, logo nos envolvemos com noções complexas e controversas que não podemos evitar. Infância pode ser compreendida considerando realidades tão diferentes como uma fase do desenvolvimento da criança, todo o período que vai até a adolescência ou toda a fase da vida antes de se ser adulto, ainda que, neste caso, os adolescentes não se revejam em tal situação, ou como uma posição vivencial que comporta menoridade face a outros grupos etários, mas ela não garante idêntica respeitabilidade face a grupos sociais diferentes.

O termo "desenvolvimento" é igualmente susceptível de levar a diferentes compreensões. Em geral, ele confunde-se com crescimento. Diz-se, por vezes, essa criança está muito desenvolvida, querendo dizer apenas que ela cresceu muito. Mas existem também autores que usam indiferentemente as palavras desenvolvimento e crescimento (MOULY, 1979; SAWREY; TELFORD, 1971). Outros, porém, como Rosa, Nerval (1985) e Bee (1984; 1986), preferem designar como crescimento as mudanças em tamanho, e como desenvolvimento as mudanças em 
complexidade, ou o plano geral das mudanças do organismo como um todo. Mussen (1979) associa a palavra "desenvolvimento" a mudanças resultantes de influências ambientais ou de aprendizagem, e o crescimento, às modificações que dependem da maturação. Para nós, desenvolvimento é mais que crescimento, embora não seja fácil determinar as fronteiras entre os dois processos. Essa dificuldade causa problemas à melhor definição dos estágios e à possibilidade de os discutir de forma consequente, ou seja, de compreender por que são diferentes.

A partir dos estudos da psicologia do desenvolvimento produzidos até aos anos sessenta, Mussem et al. (1974) afirmam que os estágios do desenvolvimento humano se caracterizam pela organização dos comportamentos típicos que ocorrem simultaneamente em determinada fase e decorrem de mudanças qualitativas, relativamente a estágios anteriores. Isso parece supor que o conceito de desenvolvimento implica fundamentalmente uma maturação biológica. De fato, vários autores que têm procurado sustentar sistemas de organização de fases do desenvolvimento parecem evidenciar essa relação, mas ela não é assim linear nem corresponde à essência das diferentes classificações. Temos, portanto, ainda uma discussão sobre como se define o desenvolvimento, quais os fatores que são determinantes para que ele aconteça, qual o sentido desse desenvolvimento, de onde vem a legitimidade que sustenta a concepção e a caracterização da compreensão de desenvolvimento.

Perante esse assunto, podemos pensar que estamos a caminhar sobre uma preocupação recente e exclusivamente científica (a psicologia do desenvolvimento afirmou-se verdadeiramente ao longo do século XX). Todavia, apesar de discutida a partir de pressupostos substancialmente diferentes, podemos dizer que essa problemática se coloca pelo menos desde a Antiguidade Clássica e será bastante tida em consideração em discursos variados ao longo dos séculos XVII, XVIII e XIX.

Já Ariès deu conta da presença das "idades da vida" em épocas bem antigas e de como elas se relacionavam com a evolução biológica e com as funções sociais. Embora tenhamos algumas reservas quanto a determinadas generalizações desse famosíssimo historiador da infância, aceitamos que, independentemente da qualidade da demonstração sobre a existência de uma consciência generalizada de uma vida dividida em etapas bem-delimitadas, havia um pensamento sustentado sobre a periodização da vida, relacionando-a com a compreensão do ciclo da natureza 
e com a organização da sociedade (p. 40), isso apesar de diferentes formas de designar as idades.

Tudo indica que o Renascimento propiciou o renovar da atenção sobre a criança, retomando ideias que vinham da Antiguidade. Mas isso significa também que os séculos XV e XVI estavam em condições de integrar esse pensamento e lhe conferir uma dinâmica que a conturbada Idade Média não podia contemplar. De qualquer modo, tudo indica que do século XVI para o século XVII se acentuou esse interesse pela arrumação dos percursos em determinadas idades (FERREIRA, 2000). Estava-se num período em que as preocupações religiosas reforçaram a valorização da educação, suscitando um olhar mais atento para o desenvolvimento dos mais novos.

Todavia, na centúria de seiscentos, as mais interessantes abordagens sobre as idades em relação com a educação foram escritas por Comênio. Esse genial pedagogo admite, na sua Didáctica Magna, que o período de crescimento pode ser dividido em quatro partes de seis anos cada, "infância, puerícia, adolescência e juventude" (COMÉNIO, 1985, p. 410) e associa a cada uma delas uma escola peculiar, de modo que o regaço materno fosse a escola da infância, a escola primária fosse a escola da puerícia, a escola de latim ou o ginásio fosse a escola da adolescência, a academia fosse a escola da juventude. Mais tarde, Comênio voltaria a dar relevo ao assunto das idades na "Pampaedia", quarta parte de De Rerum Humanarum Emendatione Consultatio Catholica, onde disserta sobre a educação ao longo da vida e, por isso, aí já apresenta escolas adequadas a sete idades em que divide a vida humana, "das quais a primeira compreende a concepção e a gestação no útero materno; a segunda, o nascimento e, consequente a este, a infância; a terceira, a puerícia; a quarta, a adolescência; a quinta, a juventude; a sexta, a idade adulta; a sétima, a velhice" (COMÉNIO, 1971, p. 110). Para Comênio, essas idades não se confinavam a um mero exercício retórico, porque ele as entendia como fases especialmente convenientes a determinadas aprendizagens, já que, como ele próprio dizia: "para a realização daquelas coisas para que foi apta a primeira idade, não o será a segunda, muito menos a terceira” (p. 109). Nesse sentido, o pedagogo checo investe claramente numa organização educacional que tem como eixo a sua concepção das idades da vida. É sobre ela que faz sentido a sua obra pedagógica.

$\mathrm{Na}$ verdade, se não considerarmos o campo escolar, ainda bastante incipiente, as idades já se constituíam como referencial de desen- 
volvimento não dispiciendo nas disposições normativas estipuladas por entidades de grande poder regulador, nesses séculos. Por elas, regulavamse capacidades e responsabilidades e condicionava-se o percurso de vida do indivíduo. Especialmente importante era a idade da puberdade: pelos doze/catorze anos, conforme se considerasse o sexo feminino ou o masculino, passava-se a ter mais direitos e a estar sujeito a maior responsabilização. Como já dissemos noutro lugar: a partir dessa idade, tornava-se possível o casamento, era obrigatória a comunhão anual na Quaresma, podia-se escolher livremente a sepultura e, quando órfão, tinha-se direito a receber o pagamento pelo seu trabalho, o que era substancialmente diferente do definido para a idade anterior (FERREIRA, 1987).

As idades também mereceram acolhimento entre os médicos. Ao longo do século XVIII, algumas obras médicas de língua portuguesa demonstram tanto o interesse em olhar para a evolução do indivíduo levando em consideração as idades da vida como a hesitação quanto à delimitação dos períodos e ao sentido que lhes conferiam. Um dos que se debruçou sobre o assunto na primeira metade de Setecentos foi Rodrigues de Abreu, que apresentou e descreveu, na sua Historiologia medica, as diversas idades, tendo em conta a sucessão de fenômenos físicos inerentes ao desenvolvimento do corpo. $\mathrm{Na}$ sua opinião, as principais idades eram a infância, a puerícia, a adolescência, a juventude, a viril, a consistente e a velhice verde, meia e decrépita. A infância compreendia os primeiros sete anos, a puerícia, os segundos, a adolescência, os terceiros e parte dos quartos, a juventude ia até aos 35 anos e os outros períodos sucediam-se ao ritmo dos septenários seguintes (ABREU, 733). Na segunda metade do século, Manuel José Leitão apresenta uma classificação que, embora formalmente diferente, traduz uma compreensão do desenvolvimento do indivíduo muito idêntica à de Rodrigues de Abreu. Ainda que tenha considerado uma primeira idade até aos 14 anos e uma segunda até aos 24 , ele subdividiu a primeira em infância e puerilidade a que se seguia depois a adolescência (LEITÃ̃, 1788).

Repartindo a sua vida entre os séculos XVIII e XIX, Francisco de Melo Franco foi um dos médicos que chamou a atenção para a importância da compreensão das idades pelos clínicos, porque, segundo esse autor, sem ela agiriam sem o necessário fundamento, "empregando quasi sempre sem acerto as suas diligencias, sem distinguir as molestias, que atacão particularmente certos orgãos segundo as diferentes idades" 
(p. 10). De acordo com essa perspectiva, a infância era encarada como o período durante o qual a cabeça recebia as preferências do crescimento. Segundo a argumentação de Melo Franco, isso via-se por aí se acumularem, por exemplo, "as forças necessarias para a dentição" e para a "formação dos cabellos", como também pela facilidade com que todas as doenças desse tempo implicavam com a cabeça e por "certas affecções, proprias deste orgão", somente se desenvolverem nessa idade. Já na puberdade, a "tendência das forças e movimentos que a natureza dirigia para a cabeça no tempo da infância" voltava-se para o peito, provocando a mudança do tom da voz, o alargamento do tórax, o fortalecimento dos pulmões, do coração e das grandes artérias, mas também "as hemoptyses, as dores, as inflammações, e todas as molestias de peito", que nesse período surgiam com maior frequência (p. 8-9). Especial importância assumia, no entanto, o desenvolvimento dos órgãos sexuais, que, no entender de Melo Franco, não só modificava a configuração externa destes como também conferia "huma nova ordem de sentimentos, estabelecendo nelles o centro de irritabilidade", que se difundiria por todo o corpo (p. 9).

Independentemente de as idades da vida apresentarem alguma diversidade classificatória, na maioria dos casos, estas tendiam a seguir a orientação vinda das antigas classificações, o que poderia significar muito mais uma subserviência intelectual e um exercício retórico do que um modelo analítico. Olhando, sobretudo, as referências sobre as primeiras idades, podemos dizer que nos encontramos num momento da história em que a retórica das idades se consolida, prejudicando de algum modo uma atitude mais compreensiva sobre o seu sentido, mas em que também se fazem tentativas, certamente umas mais felizes do que outras, que revelam uma vontade de elaborar sistematizações apoiadas em exercícios de observação e de reflexão pessoais.

Dentre as várias propostas que encontramos em clínicos portugueses, a de António Ribeiro de Carvalho parece-nos ilustrar tanto essa vontade de traduzir uma perspectiva pessoal do desenvolvimento do indivíduo quanto essa dificuldade de avançar com uma classificação que não se cingisse a retocar o que vinha dos autores mais antigos. $\mathrm{Na}$ verdade, ele apresentou-nos uma das classificações mais surpreendentes quer pelos períodos que estabelece quer pela denominação a que os associa. Considerando "idade" como "hum curto espaço de vida" a que 
"correspondem qualidades fizicas e moraes", entende que existem dois grandes grupos etários demarcados pelo nascimento, que denomina de "idades no utero e idades no mundo". Relativamente a estas, ainda que reconheça a dificuldade em delimitá-las, identifica doze idades para um percurso de vida de cem anos. O período do crescimento, que contemplava trinta anos, dividir-se-ia em cinco idades: a infância, que terminava aos três anos, era definida como idade da aleitação e das doenças e impertinências infantis; a puerilidade, que ocupava os dois anos seguintes, era entendida como uma idade de encanto e inocência; a adolescência, que tinha por limite superior os dez anos, era considerada a idade na qual se começava a desenvolver as ideias; depois vinha a mocidade, que terminava aos 20 anos, idade que seria dada a travessuras e a desordens; no fim desse período de crescimento vinha a virilidade, período de consolidação das forças e da compreensão das coisas ${ }^{1}$.

A primeira leitura dessa sistematização das idades pode suscitar diversas reações interpretativas. Uma delas é considerá-la como um presunçoso devaneio. Ela não parece articular-se nem com as classificações que seguem o modelo legado pela Antiguidade, nem com o que é comumente aceite na contemporaneidade. Somos especialmente surpreendidos pelos anos a que associa a adolescência, situada por Ribeiro de Carvalho entre os cinco e os dez anos, e pela designação de mocidade para denominar a segunda década de vida do indivíduo. Todavia, assim como a caracterização de cada um dos períodos segue caminhos já conhecidos, a própria classificação não é, como veremos, um mero exercício especulativo sem repercussões. A infância passa a definir um período específico, não se confundindo com a designação de criança ou menino/menina. Infância é a fase da alimentação centrada no aleitamento, da criança muito sujeita a doenças e muito mais dependente dos mais velhos que aquela que se alimenta da comida dos adultos e se movimenta e se faz entender razoavelmente. Nesse aspecto, ele está a evidenciar a necessidade de se olhar a criança tendo em consideração outros períodos do desenvolvimento desta, o que é algo que se vai afirmar apenas nos decênios seguintes. Recorde-se que a classificação de Hallé2, que teve bastante aceitação nas primeiras décadas de Oitocentos, só indicava duas fases: a $1^{\mathrm{a}}$ infância, de 1 a 7 anos, e a $2^{\mathrm{a}}$ infância ou puerícia, de 7-15 anos, para os meninos, ou de 7-13 anos, para as meninas. Mesmo Becquerel, que escreveu em meados do século XIX, teve dificuldade em 
definir as idades da criança. Se este higienista estabeleceu três idades para o período de crescimento que vai até a adolescência, a primeira dizia respeito ao recém-nascido, a segunda, designada de primeira infância, terminava aos dois anos e a terceira, ou seja, a segunda infância, abarcava todo o tempo até aos doze/quinze anos.

Essas posições traduzem uma situação que revela um interesse cada vez mais generalizado para com o crescimento da criança, mas também a dificuldade em enquadrar especificidades do desenvolvimento da mesma. Essa dificuldade sobre a definição da primeira infância foi demonstrada por Luc (1998), que, num levantamento de quase três centenas de obras editadas entre meados de Setecentos e o fim de Oitocentos, reconhece que ela podia assumir mais ou menos três anos de diferença. Ora, independentemente dos argumentos utilizados ou da autoridade convocada, a ideia de uma fase delimitada pelo desmame denominada de primeira infância encontra crescente aceitação na segunda metade de Oitocentos.

Em Portugal, várias teses das Escolas de Medicina tendem a suportar essa ideia de uma primeira infância associada aos dois ou três primeiros anos de vida da criança. Entre as mais interessantes dissertações relativas à primeira infância apresentadas na Escola Médico-Cirúrgica do Porto está a redigida por Aurélia de Moraes Sarmento, na última década do século XIX. Nesse seu trabalho, simplesmente denominado Hygiene da primeira infancia (1891), a autora manifesta claro propósito de se confinar só a esse período, mas sabe que está perante um "limite artificial" porque "o trabalho de desenvolvimento organico na creança se opera insensivelmente e sem transição acentuada" (Introdução). Embora admita, por isso, que, anatomicamente, se possa demarcar a primeira infância pela queda da primeira dentição, considerando "a questão pelo lado hygienico", entende que o limite se deve situar no fim da lactação, pelo que em coerência com a sua posição, o seu trabalho termina com um capítulo sobre o desmame, no qual, no entanto, se recusa a "estabelecer um limite fixo com relação à época em que as creanças devem ser desmamadas" (p. 77). Ao não indicar os anos do limite da primeira infância, ao contrário do que se pode supor, essa médica revela que mais importante do que seguir um rígido critério cronológico, interessava atender a indicadores funcionais que afetavam a vida da criança. Ora, a alimentação era dos aspectos mais relevantes na sobrevivência dos mais 
pequenos e, por isso, um dos principais cuidados que, ao longo de Oitocentos, suscitaram especial interesse médico e que levaram a prestar particular atenção a esse período específico da infância.

O século XIX assiste, no entanto, a grandes transformações ideológicas, sociais e científicas. O desenvolvimento da ciência, a emergência de novas realidades econômicas, a visibilidade dos problemas sociais provocados pela industrialização, a necessidade de aumentar a qualidade sanitária da população fizeram com que os médicos de Oitocentos se preocupassem em alargar o campo da sua intervenção, que se estende, a partir de agora, quer às crianças menos favorecidas quer a novos espaços frequentados pelos mais pequenos. Mas o que vai ter mais implicações para a compreensão do desenvolvimento da infância é o fenômeno da escolarização. $\mathrm{Na}$ segunda metade do século XIX, a escola surgia como a instituição que generalizaria o progresso e a cidadania, condições essenciais a qualquer nação que se pretendesse desenvolvida e soberana. Diante da inevitabilidade da escolarização, médicos inseridos no movimento higienista, muito em sintonia com o alinhamento intelectual positivista, vão pretender delinear uma abordagem pedagógica que se pretende fundada na fisiologia e na busca da medida adequada ao desenvolvimento da criança. Desse modo, vai emergir uma tendência para se instituir um saber pedagógico articulado com a tecnologia médica e isso contribuirá muito para o investimento no estudo científico da criança. Acresce, por outro lado, que a nova sensibilidade filantrópica, aliada às preocupações educacionais resultantes das dinâmicas sociais, culturais e políticas do século XIX, propiciam o surgimento de um movimento pedagógico que procura fomentar instituições para crianças que ainda não estão em idade de frequentar a escola primária, mas onde se devia promover uma educação que tivesse um claro propósito de atender ao desenvolvimento sensorial, intelectual e social dos que as frequentassem. Desse modo, ampliava-se o campo de intervenção pedagógica e o do estudo da criança.

Vemos, portanto, que antes da constituição da psicologia infantil e da pediatria, racionalidades que têm como preocupação fundamental compreender a criança e o seu processo de desenvolvimento, havia esforços de construção de um saber médico sobre a infância, que, a partir da segunda metade do século XIX, se procurou consolidar e ampliar, aproveitando tanto as necessidades da sociedade coetânea quanto a 
autoconfiança que advinha do progresso das técnicas em que se fundava. A reforçar ou a sustentar essa tendência que se vinha esboçando sobre a necessidade de se compreender a criança, os intelectuais preocupados com a pedagogia escolar e os médicos que acreditavam no esforço higienista sentiram-se estimulados pela sedução do cientificismo e do evolucionismo, por sua vez muito fundados no acentuado desenvolvimento tecnológico e científico do século XIX.

É nesse contexto que se vai ensaiar uma ciência da criança e emergir a psicologia genética. $\mathrm{Na}$ verdade, a psicologia da criança resulta tanto de um processo de desenvolvimento científico quanto de uma dinâmica sociocultural bem ampla. Interessa aqui só relembrar que estamos perante um processo de desenvolvimento científico que já era claro no século XVIII, mas que será acelerado ao longo de Oitocentos (Pasteur, Koch, Darwin); que estamos perante emergências de quadros ideológicos que vêm da racionalidade iluminista, mas que agora se mostram com desenvoltura mais reivindicativa e igualitarista (liberalismo, republicanismo, socialismo); que estamos perante a aposta na escolarização, no investimento educacional, tendo em vista uma mão de obra mais capacitada e em obter adultos mais capazes de constituir a nação num quadro civilizacional moderno.

Em boa parte, tudo isso se articula com a teoria evolucionista. J. M. Baldwin escreveu no seu livro, intitulado Desenvolvimento Mental na Criança e na Espécie (1895), que a amplitude da concepção da psicologia estava certamente de acordo com as concepções há muito aceites em outros ramos da pesquisa científica, mas que uma fase dessa ampliação da pesquisa psicológica só se tornava notória quando interpretada à luz da doutrina da evolução. Essa era uma fase que denominaria de "fase genética ou da evolução". Segundo ele, a "ideia anterior de alma supunha uma substância fixa, com atributos fixos". Desse modo, o "conhecimento da alma era imediato na consciência, e era adequado". A ideia genética invertia tudo isso. "Em vez de uma substância fixa, temos a concepção de uma actividade em crescimento e desenvolvimento. Em vez de começar com a exibição complexa desse desenvolvimento, obteremos mais instrução na actividade mais simples que é, ao mesmo tempo, a mesma actividade". Ou seja, para se compreender o pensamento do adulto era preciso compreender como ele se formava.

No princípio do século XX, Robert Gaupp também associa a emergência da psicologia da infância às ideias evolucionistas e à 
aproximação às ciências naturais. Isso comporta duas consequências: empurra cada vez mais o estudo da psicologia para os métodos indutivos das ciências e passa a considerar o estudo da criança tanto em função da necessidade de compreender a especificidade da infância quanto para compreender o desenvolvimento psíquico do ser humano. No fundo, a emergência da psicologia da criança é favorecida pela relevância que constitui para a compreensão da ontogênese (desenvolvimento do indivíduo) e da filogênese (desenvolvimento da espécie). É que, para alguns intelectuais, não só o desenvolvimento do indivíduo comportava as fases do desenvolvimento da humanidade como a criança comportava um esboço do desenvolvimento do indivíduo. Essa relação da compreensão da ontogênese associada à filogênese perde vigor ao longo das primeiras décadas do século XX. Mas as razões que justificaram a compreensão do desenvolvimento vão continuar a desafiar várias personalidades marcantes do pensamento psicológico e a pretensa cientificidade não diminuirá as divergências entre as diferentes abordagens. Veja-se, por exemplo, como os estágios psicanalíticos associados a zonas erógenas em muito diferem dos estágios piagetianos sobre o desenvolvimento da inteligência e que ambos são diferentes dos apresentados pelo sistema de Wallon, em que há sobreposições e interligações complexas, com cada estágio devendo ser visto como um comportamento total.

Apoiando-se no saber médico-pedagógico que vinha de décadas anteriores, e sobretudo dos estudos de ciências-médicas, da antropologia e da psicologia experimental, alguns médicos e pedagogos portugueses esforçaram-se para que, em Portugal, singrasse a Pedologia como ciência natural da criança. Entre eles figuraram médicos como Aurélio da Costa Ferreira, Costa Sacadura e Alberto Pimentel Filho e pedagogos como Faria de Vasconcelos e Alves dos Santos. Todos eles produziram estudos sobre o desenvolvimento da criança, mas aqui tenderemos a concentrarnos na produção deste último, porque nos apresenta um pensamento mais global e sistematizado e informação original. Deve-se acrescentar que a Pedologia foi ensinada, em Portugal, no âmbito de cursos de formação de professores, durante as primeiras décadas do século XX, acreditando-se que ela seria fundamental para que os professores primários pudessem cuidar de adequar o ensino às capacidades dos seus alunos. Algumas lições desses cursos foram impressas, dando-se a conhecer a públicos mais vastos. Sublinhe-se, entretanto, que Alberto Pimentel Filho publicou, em 
1929, suas lições de Pedologia apresentadas na Escola Normal de Lisboa e que a obra, intitulada Pedologia (esboço de uma história natural da criança), veio a merecer reedição em 1935, o que testemunha o interesse pelo seu conteúdo e o quanto ainda parecia interessante afirmar-se um saber global sobre a compreensão do desenvolvimento da infância.

Segundo Alberto Pimentel (1935, p. 11), foi "o norte-americano Oscar Chrisman, discípulo do célebre Stanley Hall, quem, em 1893, propôs que a história natural da criança fosse batizada com a designação de Pedologia", denominando, assim, uma área de investigação que se vinha desenvolvendo, pelo menos desde o século XVIII, e que encontrou as condições propícias para o seu desenvolvimento na segunda metade do século seguinte. Também em Portugal houve quem, ao longo desse período, tentasse acompanhar esse interesse pelo estudo científico da criança, mas foi sobretudo nas primeiras décadas do século XX que se investiu de forma mais consequente na obtenção de um conhecimento que integrasse a realidade portuguesa. No fim da segunda década, vários estudos sobre a criança portuguesa permitiam ao professor da Universidade de Coimbra e responsável pelo Laboratório de Psicologia Experimental da mesma instituição publicar um livro intitulado Educação Nova. As bases. O corpo da criança (1919), que deveria ser seguido de outro volume sobre o desenvolvimento mental da criança, o que não veio a acontecer por o autor ter falecido antes de terminar esse trabalho. O livro ilustra bem quanto Alves dos Santos aposta na Pedologia como ciência natural da criança. Para ele, a criança podia ser "estudada em si mesma", sem outro intuito que não fosse "o de a conhecermos, do mesmo modo que o botanista estuda as plantas, ou o entomólogo, os costumes dos animais". Nesse caso, o estudo da criança não poderia deixar de "submeter-se às regras do método" exigidas em qualquer investigação científica (p. 14). De qualquer modo, esse campo constituía-se a partir de diferentes abordagens e isso levava a que pudesse ser dividido em Pedologia pura, quando apenas visava ao estudo desinteressado da criança, e em Pedologia aplicada, quando o estudo visava a determinado fim. A Pedologia Pura, sendo o "estudo integral da criança, compreendia a biologia infantil, a psicologia infantil e a sociologia infantil; a Pedologia Aplicada compreendia a pediatria, a pedotecnia judiciária e a pedagogia experimental. Todas essas especialidades tinham ainda subdivisões, pelo que a Pedologia se constituía como ciência totalizante da criança, como 
domínio do conhecimento que devia organizar a compreensão fundamentada sobre os que se encontravam em desenvolvimento e a orientar todos aqueles que atuavam com estes.

Curiosamente, toda essa aposta no estudo científico da criança não parecia suficiente para alterar um modelo de classificação das idades que já encontráramos num médico português do princípio do século XIX. Para Alves dos Santos, as fases da vida das crianças, definidas a partir do "critério fisiológico da dentição, combinado com o da maturidade sexual", eram as seguintes:

recém-nascença (até ao fim do primeiro mês, depois do nascimento);

infância (desde o fim do primeiro mês, até aos três anos);

puericia (desde os três anos, até aos sete);

adolescência (desde os sete, até à idade que oscila, para os rapazes, entre os doze e os catorze anos; para as raparigas, entre os onze e os treze);

puberdade (desde o fim da adolescência, até a uma época que, segundo as circunstâncias, também varia, em relação a cada sexo; não indo, porém, entre nós, em regra, além dos dezasseis anos, para os rapazes, e dos quinze para as raparigas);

nubilidade (desde os quinze ou dezasseis anos, até aos vinte).

Essa sistematização das idades surpreende-nos, desde logo, pela semelhança com a apresentada por António Ribeiro de Carvalho, nos inícios de Oitocentos. As diferenças traduzem sobretudo uma maior atenção a períodos mais específicos, como o do primeiro mês após o nascimento e os anos da emergência da puberdade. Mas ambas as sistematizações se aproximam ao apresentarem uma sucessão de idades na qual a infância terminava aos três anos, seguindo-se-lhe a puerícia e, depois, a adolescência antes da puberdade. A classificação de Alves dos Santos revela maior conhecimento das alterações anatômicas e fisiológicas da criança e apresenta limites cronológicos mais razoáveis para o fim da puerícia e da adolescência, mas reforça a ideia de que o médico Oitocentista estava já a romper com a antiga classificação das idades e a tentar caminhar em direção a uma que resultasse da experiência e dos métodos da nova medicina. Todavia, não deixa de suscitar estranheza que nas duas classificações se coloque a adolescência como um período anterior à puberdade, o que não condiz nem com as propostas mais antigas nem com a concepção atual. Alberto Pimentel Filho (1935, p. 112) percebeu que a designação de adolescência era equívoco e sentiu 
necessidade de a explicitar. Para isso, recorreu a uma citação de Godin, que, precisando a significação do termo adolescência, escreveu:

A que período da vida da criança convém pois o têrmo adolescência?

Se entendermos dever dar à palavra 'adolescência' o seu sentido original, a saber período de crescimento, de 'adolescere', crescer, e se nos reportarmos apenas ao alongamento da estatura para determinar o momento dêste período, deveríamos lòcamente designar pelo mesmo vocábulo 'adolescência' a extensão inteira da vida da criança sem excluirmos dela o período do nascimento aos cinco anos, e menos ainda a fase êmbrio-fetal ou intrauterina.

O uso está, na espécie, em contradição flagrante com a lógica, e o melhor seria talvez suprimir uma palavra tão completamente desviada do seu sentido real.

Mas está admitido que o termo adolescência se aplique à última fase da infância, à fase peri-pubertária, e que seja consagrado especialmente à última impulsão um tanto importante de alongamento pelos membros inferiores.

Alves dos Santos também parece ter dúvida quanto à designação de adolescência porque, quando tenta a explicitação desse período, começa por justificar a sua utilização por ser costume associá-la à "fase peri-pubertária" (p. 21). Mas onde a evidência de dúvida surge mais eloquente é na parte em que ele trata dos cânones antropométricos da criança. De fato, ao apresentar diversas medidas e algumas conclusões sobre as características mais específicas para diferentes fases, ele passa da puerícia para a puberdade, inserindo aqui duas vezes a expressão adolescência associada a qualidades normalmente relacionadas ao período iniciado com a puberdade. A ambiguidade da sua posição deriva de ele ter dificuldade em articular discursos diferentes sobre o desenvolvimento da criança. Ao fazer uma leitura mais próxima dos dados antropométricos parece não ter outra solução que estabelecer uma proximidade ambígua entre a adolescência e a puberdade. Assim sendo, não fazia sentido manter uma fase distinta entre a puerícia e a idade pubertária. A puerícia, como sinteticamente a definiu Alves dos Santos, "representa na vida evolutiva da criança, a idade média, ou o período de transição (ainda não influenciado pela lei dos sexos) entre a impulsividade dos instintos, temperada já por uma certa autonomia da consciência, e a idade crítica do crescimento", que seria, no seu entender, aquela em que se operaria "a transformação definitiva do corpo da criança no organismo do adulto” (p. 
100-101). Essa idade crítica é, precisamente, a que ele designa por puberdade, mas que ele já pressentiu que vai ser adolescência. As suas últimas linhas relativas aos cânones antropométricos da criança são bem elucidativas disso. Escreve ele, a finalizar o Cânon antropométrico da Puberdade e referindo-se exatamente a este período:

Época das grandes transformações do organismo; e, sob a influência da diferenciação, estádio decisivo da constituição específica de cada sexo, a puberdade marca, na marcha da evolução, o momento preciso, em que a Natureza entra de preparar o ser humano para o exercício da função, de que depende a perpetuidade da espécie.

Esta é a sua característica fundamental e diferencial, eixo sôbre que gira tôda a complexidade e contraditória psicologia do adolescente (p. 104).

Olhando tanto para a posição de Alves dos Santos quanto para a evolução histórica da compreensão do desenvolvimento da criança, podemos verificar a complexidade que envolve a elaboração de uma concepção de infância. É preciso mais que uma personalidade, ainda que muito culta que seja ou mais que uma vontade dotada de grande generosidade para que se possa estabelecer um paradigma de infância que se imponha somente pela bondade da ideia. Não é, pois, razoável pensar que foi apenas a falta de vontade ou de generosidade que impediu que se caminhasse mais cedo para um pensamento que sustentasse de forma inabalável e consequente a importância de se atender ao desenvolvimento da criança. Não é tão pouco consistente a ideia de que a preocupação com o desenvolvimento da criança seja apenas uma construção da ciência moderna e, em particular, da psicologia genética. Na verdade, a compreensão do desenvolvimento da criança ocupou pessoas de variada formação intelectual e de diferentes tempos e contextos e esteve na base dos pensamentos que sustentaram a organização de percursos de formação e socialização de diferentes momentos da história. Todavia, não é problemático admitir-se que houve épocas mais propícias de que outras para o aparecimento de discursos mais dados a melhorar a compreensão da criança e que esta nem sempre se construiu linearmente, a partir de um mero acumular de conhecimentos. A criança foi sempre pensada a partir de determinados contextos e foram as possibilidades de inteligibilidade que estes encerravam que permitiram construir discursos diversos, na forma ou no conteúdo, que umas vezes coincidiam outras divergiam, mas 
que, na sua diversidade e na sua relação com as alterações societais, foram constituindo um pensamento consentâneo com a capacidade científica e os condicionalismos ideológicos de cada época.

O estudo das "idades da vida", ou melhor, das idades do crescimento do indivíduo permite-nos ver qual o sentido que se atribuía a diferentes momentos da evolução da criança. É por isso que não as devemos ler como simples e ingênuas manifestações de um incipiente conhecimento do desenvolvimento da criança ou como exercícios retóricos sem relação com os contextos em que são expressos. Elas revelam, como já o dissemos, um pensamento sustentado da evolução da pessoa, relacionando-a com a compreensão do ciclo da natureza e com a organização da sociedade e condicionaram fortemente posteriores leituras fisiológicas e psicológicas sobre o desenvolvimento do indivíduo. Sob a designação de etapas, fases ou estágios, a ciência moderna tentará caracterizar os períodos significativos do desenvolvimento da criança, contribuindo para consolidar e afirmar, de forma peremptória, a especificidade da infância e definir e delimitar, de forma mais precisa, diferentes aspectos do desenvolvimento infantil. Tal como evidenciamos neste nosso trabalho, todo esse percurso sobre a compreensão do desenvolvimento da criança não se fez sobre unanimidades e sem controvérsia. Em meados do século XX, depois de décadas de grande investimento no estudo do desenvolvimento psicológico da criança, veio Tanner defender que o crescimento físico, fisiológico e nervoso da criança se efetuava de uma forma contínua e progressiva, pelo que não lhe parecia razoável que se defendesse uma teoria da divisão em estágios psicológicos (OSTERRIETH et al., 1956). Como é compreensível, a posição de Tanner, segundo Tran-Thong (1983), lançou a confusão entre os psicólogos e a dúvida sobre a existência dos estágios, tanto mais que existiam grandes divergências na delimitação destes, assim como na formulação dos critérios em que se baseava a sua elaboração. Esse problema não era novo e já fora aflorado por autores de épocas anteriores. Provavelmente saía ampliado pela quantidade de pessoas envolvidas na discussão. De qualquer modo, Wallon não viu nas conclusões de Tanner um verdadeiro obstáculo à elaboração de estágios. Para ele, mesmo que a maturação do sistema nervoso fosse contínua, "a simples relacionação dos centros anteriormente disjuntos pode fazer eclodir actividades completamente novas que transformam as condições de existência e o 
comportamento da criança" (WALLON, 1956, p. 224). Nos autores mais antigos, o que interessou também foi definir períodos que, baseados no crescimento físico, traçassem qualidades expectáveis e comportamentos exigíveis às crianças. Se tivermos só em consideração essa produção discursiva, a criança foi sempre associada à noção de devir. Criança é aquela pessoa que está a ser criada, aquela que não tem ainda todas as capacidades exigíveis ao adulto. As idades, as fases, os estágios são tentativas de sinalizar as qualidades do seu desenvolvimento.

\section{Referências}

ABREU, José Rodrigues de. Historiologia medica, fundada, e estabelecida nos principios de George Ernesto Stabl, famigeradissimo escritor do presente seculo, e ajustada ao uso pratico deste paiz. tomo primeiro, Lisboa Occidental, 1733.

ALMEIDA, Francisco José de. Tratado da educação fysica dos meninos, para uso da nação portugueza. Lisboa: Academia Real das Sciências, 1791.

ARIÉS, Philippe História social da criança e da família. Rio de Janeiro: Guanabara, 1981.

BECCHI, Egle; JULIA, Dominique. Histoire de l'enfance, histoire sans paroles? In: Histoire de l'enfance en Occident - de l'antiquité au XVII siècle, v. I. Paris: Seuil, 1998.

BECCHI, Egle. Le XIX siècle. In BECCHI, Egle; JULIA, Dominique. Histoire de l'enfance en Occident - du XVIII siècle à nos jours, v. II. Paris: Seuil, 1998.

BECQUEREL, A. Traité elementaire d'hygiene privée et publique. 3 ed. Paris: P. Asselin, 1864. BEE, H. A Criança em Desenvolvimento. São Paulo: Harbra, 1986.

BIAGGIO, A.B. Psicologia do Desenvolvimento. 3 ed. Petrópolis: Vozes, 1976.

BOTO, Carlota. Nova história e seus velhos dilemas. Revista USP (Universidade de São Paulo), n. 23, setembro/outubro/novembro, 1994.

CARVALHO, Francisco da Silva. A mortalidade das creanças e a assistencia publica. Porto: Typographia de Cristovão A. Rodrigues, 1894.

CASTRO, Luiz de Barros de Faria e. Breves considerações sobre a alimentação da primeira infância. Porto: Typographia de viúva gandra, 1880.

CHASSAGNE, Serge. Le travail des enfants aux XVII e XIX siècles. In : BECCHI, Egle; JULIA, Dominique. Histoire de l'enfance en Occident - du XVIII siècle à nos jours, v. II. Paris: Seuil, 1998.

CHAVES, Armando. Creanças, educação e hygiene. Porto: Typographia F. Vasconcellos, suc., 1902.

COMÉNIO, João Amós. Pampaedia (Educação Universal). Coimbra: Faculdade de Letras da Universidade de Coimbra, 1971.

COMÉNIO, João Amós. Didáctica Magna.Tratado da arte universal de ensinar tudo a todos. 3 ed. Lisboa: Fundação Calouste Gulbenkian, 1985.

CRUZ, Emygio Pereira. Hygiene das escolas. Porto: Typographia occidental, 1879.

FERREIRA, António Gomes. A criança no conhecimento médico de seiscentos. Revista Portuguesa de Pedagogia, ano XXIII, 1989.

FERREIRA, António Gomes. Gerar, Criar, Educar. A criança no Portugal do Antigo 
Regime. Coimbra: Quarteto Editora, 2000.

FERREIRA, António Gomes; PEREIRA, Ana Maria Patrício. Um relance sobre a criança do século XVI. Revista Portuguesa de Pedagogía, ano XXI, p. 169-198, 1897.

FRANCO, Francisco de Melo. Tratado de educação fysica dos meninos para uso da nação portugueza. Lisboa: Academia Real das Sciências, 1790.

FREIRE, Antonio José Pimenta. Breves consideracõos sobre a sedentariedade cerebral e esfalfamento cerebral. Porto: Papelaria e typographia Azevedo, 1902.

GAUPP, Robert. Psicologia del niño. Barcelona-Buenos Aires: Editorial Labor, 1927.

GONDRA, José G. Artes de civilizar - medicina, higiene e educação escolar na Corte Imperial. Rio de Janeiro: Eduerj, 2004.

GOUV A, Maria C. S. Tempos de aprender - a produção histórica da idade escolar. Revista Brasileira de História da Educação. Campinas: Autores Associados, 2004.

LEITÃO, Manuel da Silva. Arte com vida ou vida com arte, muy curiosa, necessaria, e proveitosa não só a medicos, e cirurgioens, mas ainda a toda a pessoa de qualquer estado, ou condição, que seja, principalmente aos casados; e mais que a todos, aos noivos de pouco tempo, em a qual se encontra bum regimento de paridas. Lisboa Occidental, 1738.

LEITÃO, Manuel José. Tratado completo de anatomia, e cirurgia com bum resumo da história da anatomia, e cirurgia, seus progressos, e estado della em Portugal. 4 tomos, Lisboa, 1788.

LEMOS, Maximiano. História da medicina em Portugal, doutrinas e instituições. Lisboa: Manuel Gomes, Editora, 1899. 2 vols.

LIMA, Antonio Martins de Souza. A bygiene e o trabalho das creanças. Porto: Imprensa commercial, 1880.

LIMA, Manoel Carvalho d'Araujo.Creches. Porto: Typographia Oriental, 1878.

LOBO, Alfredo Duarte. A saude da infancia ou conselhos ás mães sobre a conservação dos filhos durante os ultimos tempos da prenhez e sua educação physica no primeiro período da vida commum. Porto: Typographia de José Pereira da Silva \& $\mathrm{F}^{\circ}, 1865$.

LUC, Jean-Noël. Les premières écoles enfantines et l'invention du jeune enfant. In: BECCHI, Egle; JULIA, Dominique. Histoire de l'enfance en Occident - du XVIII siècle à nos jours, v. II. Paris: Seuil, 1998.

MARTINS, Álvaro. A bigiene e a educação psíquicas nos três primeiros anos de vida. Porto: Papelaria e typographia acadêmica, 1898.

MOULY, G.J. Psicologia Educacional. São Paulo: Pioneira, 1979.

MUSSEN, P.H.; CONGER, J.J.; KAGAN, J. Desenvolvimento e personalidade da criança. 4 ed. São Paulo: Harper \& Row do Brasil Ltda, 1977.

MUSSEN, P.H. O desenvolvimento psicológico da criança. Rio de Janeiro: Guanabara, 1979.

PAIVA, Manuel Joaquim Henriques de. Aviso ao povo ou sumario dos preceitos mais importantes, concernentes á creação das crianças, ás differentes profissões, officios, aos alimentos e bebidas, ao ar, ao exercicio, ao somno, aos vestidos, á intemperança, á limpeza, ao contagio, ás paixões, ás evacuacõos regulares, e, que se devem observar para prevenir as enfermidades, conservar a saude, e prolongar a vida. Lisboa, 1787.

PARRA, Francisco Ignacio. Algumas palavras sobre os efeitos, tratamento e meio de prevenir o esfalfamento mental. Porto: Papelaria e Typographia Morgado, 1898.

PIMENTEL FILHO, Alberto. Pedologia (esboço de uma história natural da criança). II vols. 2 ed. Lisboa: Livraria Editora Guimarães \& C $C^{\mathrm{a}}, 1933$.

PROENÇA, António Augusto. Algumas palavras sobre a bygiene da primeira infância. Porto: 
Typographia de A. F. Vasconcellos, succ., 1901.

RIBEIRO, Guilherme Urbano da Costa. A mortalidade infantil no Porto. Porto: Typ. A vapor da real officina de S. José, 1902.

ROSA, M. Psicologia Evolutiva. Petrópolis: Vozes, 1986.

SANTOS, Alves. Educação Nova. As bases. O corpo da criança. Lisboa: Livrarias Aillaud e Bertrand, 1919.

SARMENTO, Aurélia de Moraes. Hygiene da primeira infância. Porto: Imprensa Portugueza, 1891.

SAWREY, J.M.; Telford, C.W. Psicologia Educacional. Rio de Janeiro: Ao Livro Técnico S.A., 1971.

TRAN-THONG. Estádios e conceito de estádio de desenvolvimento da criança na psicologia contemporânea. Porto: Edições Afrontamento, 1983. 2 vols.

\section{Notas}

1 Ms. BFMUP, António Ribeiro de Carvalho, Liçoes elementares do $2^{\circ}$ anno, 1820, p. 320 323.

2 Jean-Noël Hallé foi professor da Faculdade de Medicina de Paris e, em 1787, elaborou uma classificação das idades que teve bastante aceitação durante várias décadas.

Recebido: $27 / 10 / 2009$

Aprovado: 25/11/2009

Contato:

Universidade de Coimbra

Rua do Colégio Novo, Apartado 6153

3001-802

Coimbra/Portugal 